Research Paper

\title{
Prognostic Effect of Albumin-to-Globulin Ratio in Patients with solid tumors: A Systematic Review and Meta-analysis
}

\author{
Jiaxi He $\mathrm{He}^{1,2,3^{*}}$, Hui Pan ${ }^{1,2,3^{*}}$, Wenhua Liang1, ${ }^{1,2,3}$, Dakai Xiao ${ }^{1,2,3}$, Xuewei Chen ${ }^{1,2,3}$, Minzhang Guo ${ }^{1,2,3}$, Jianxing \\ $\mathrm{He}^{1,2,3}$ \\ 1. Department of Thoracic Surgery, the First Affiliated Hospital of Guangzhou Medical University, Guangzhou, China; \\ 2. Guangzhou Institute of Respiratory Disease \& China State Key Laboratory of Respiratory Disease, Guangzhou, China \\ 3. National Clinical Research Center for Respiratory Disease, Guangzhou, China; \\ *These authors contributed equally to this work. \\ $\triangle$ Corresponding author: Jianxing He, Email: hejxkevin@gird.cn, Tel: +86-20-83062114; No 151, Yanjiang Rd, Guangzhou 510120, Guangdong Province, PR \\ China. \\ (c) Ivyspring International Publisher. This is an open access article distributed under the terms of the Creative Commons Attribution (CC BY-NC) license \\ (https:// creativecommons.org/licenses/by-nc/4.0/). See http://ivyspring.com/terms for full terms and conditions.
}

Received: 2017.05.22; Accepted: 2017.08.25; Published: 2017.10.23

\begin{abstract}
Background: Albumin and globulin are main components of serum protein. The level of albumin and globulin partially represents the nutrition status and immune system. Albumin-to-globulin ratio (AGR) has been reported as a prognostic factor in various cancers. We therefore performed a meta-analysis to elucidate the prognosis effect of AGR on survival outcomes in solid tumors.

Method: Six electronic database were searched for the relevant articles that assessing the prognostic value of pre-treatment AGR in solid tumor patients. The primary outcome was overall survival (OS) and the secondary outcomes were cancer-specific survival (CSS), disease-free survival (DFS) and disease-metastasis-free survival (DMFS). The time-to-event outcomes were summarized in hazard ratio $(\mathrm{HR})$ and $95 \%$ confidence interval $(\mathrm{Cl})$.

Result: A total of 13890 solid tumor patients in 24 studies were included. The AGR higher than the cut-off values ranging from 1.15-1.75 was related to better OS $(\mathrm{HR}=0.58,95 \% \mathrm{Cl} 0.537-0.626$, $p<0.0001)$, CSS (HR=0.287, 95\%Cl 0.187-0.438, $p<0.0001)$, DFS ( $H R=0.792,95 \% \mathrm{Cl} 0.715-0.878$, $p<0.0001)$ and DMFS $(H R=0.595,95 \% \mathrm{Cl} 0.447-0.792, p<0.0001)$. According to the cut-off values, subgroup analysis showed that $A G R$ had significant prognostic effect on $O S$ in each cut-off intervals $(\leq 1.20,1.20-1.40$ and $\geq 1.40)$.

Conclusion: Pre-treatment AGR is an effective prognostic factor and high AGR represents an ideal clinical outcome in the solid tumor patients.
\end{abstract}

Key words: meta-analysis, prognosis, survival, solid tumor, albumin-to-globulin ratio(AGR)

\section{Introduction}

Albumins and globulin are the main components of serum proteins. Albumins reflect the nutrition status of the human body, which are functioning as the regulators of colloid osmotic pressure of blood. Moreover, they also bind cations, fatty acids, bilirubin, hormones and pharmaceuticals and act like the transporters. Besides, it also involves in various sorts of physiological activities of human bodies.
Lower albumin levels indicated poor nutrition status which had been reported to predict poor survival in various type of cancers in the previous studies ${ }^{[1-5]}$. Globulin family has several members including alpha, beta, and gamma globulins. Among them, gamma globulin accounts for the largest proportion. It is known as immunoglobulin or antibody and secreted by $B$ cells of the adaptive immune system. Therefore, 
it plays an important role in immunity. An increased level of globulin has been proved to be related to chronic inflammation ${ }^{[6-8]}$. Chronic inflammation increases the acute phase proteins in human bodies (eg: C-reactive protein, serum amyloid, complement C3, fibrinogen, ceruloplasmin et.al.). They are all parts of globulins which are markers of chronic inflammation when they are elevated in various levels. It reflects the accumulation of various proinflammatory cytokines, such as interleukin(IL, especially IL-6 and IL-1 $\beta$ ) and tumor necrosis factor ${ }^{[9-10]}$. Besides chronic inflammation, globulin has been reported to be increased in various types of cancer especially in hematologic cancers. In multiple myeloma, lymphoma and light chain disease, some particular globulins would significantly increase and could be detected not only in the serum, but also in the urine or other body fluid [11-13].

As closely associated with the nutrition status and immune system activity, albumin and globulin had remarkable value in the prognosis of cancers. Albumin-to-globulin ratio (AGR) which was calculated from the equation of albumin/(total proteins - albumin), had been suggested and considered as an effective combination of two strong prognostic factors. In the hematologic tumor, it had been reported that lower AGR predicted poorer survival outcomes in lymphoma ${ }^{[14]}$.

In terms of non-hematologic solid tumors, numbers of researches have been performed to study the prognostic value of AGR ${ }^{[15-36]}$. However, there is still no consensus on the prognostic effect of AGR in solid tumors. Besides, the cut-off values in studies were undetermined. Therefore, we performed a systemic review and meta-analysis to elucidate the prognostic value of AGR on clinical outcomes in solid tumor patients. Moreover, we intend to verify its prognostic effect in different cut-off intervals.

\section{Materials and Methods}

\section{Data source}

The electronic search was performed using PubMed, Embase, Web of Science, Cochrane Central Register of Controlled Trial, Cochrane Database of Systematic Reviews, ACP Journal Club and Database of Abstracts of Reviews of Effects and PMC database from the date of the earliest publication (1962) to April 2017. This study was conducted in accordance with evidence-based minimum set of items for reporting in systematic reviews and meta-analyses (PRISMA).

\section{Search strategy}

In order to achieve the maximum sensitivity, we used the following search strategy: ("albumins"[MeSH
Terms] OR "albumins"[All Fields] OR "albumin"[All Fields]) AND ("globulins"[MeSH Terms] OR "globulins"[All Fields] OR "globulin"[All Fields]) AND ("ratio"[All Fields]) AND ("neoplasms"[MeSH Terms] OR "neoplasms"[All Fields] OR "cancer"[All Fields]). All the articles were filtered by inclusion and exclusion criteria. When duplicated data was encountered, only the latest and complete reports were included for data extraction and assessment.

\section{Inclusion and exclusion criteria}

The selection criteria were as follow: (1) patients with non-hematologic solid tumors; (2) prognostic effect of AGR was evaluated on overall survival (OS), disease-free survival (DFS) and/or recurrent-free survival (RFS), disease-metastasis-free survival (DMFS), and cancer-specific survival (CSS); (3) the studies were reported in terms of hazard ratio (HR) and its $95 \%$ confidence interval (CI) or the Kaplan-Meier Curve which the HR was calculated from or the $p$ values and cohort numbers from the outcomes with Parmar's method[32]; (4) the cut-off value of AGR which had been reported. The candidate articles would be excluded if they met the following exclusion criteria: (1) patients with hematologic cancers; (2) case reports, abstracts, expert opinion, conference presentation, guidelines and reviews; (3) less than 20 patients in either arm; (4) insufficient data for estimating the $\mathrm{HR}, 95 \% \mathrm{CI}$ or $\mathrm{p}$ value; (5) no cut-off value of AGR reported or only reported as a continuous variable; (6) non-English publications; (7) non-human research.

\section{Data extraction}

All the data were independently extracted from the articles, tables, figures and supplement of the publications by three inspectors (DK. X, XW. C and MZ. G). Discrepancies between reviewers were resolved by the discussion and consensus with the senior investigators (JX. H, H. P and WH. L). The publication characteristics and time-to-event data were extracted and recorded as: first author, publication year, study type, cancer site, study duration, institute, disease stage (non-metastatic, metastatic or mixed), number of patients, group number, average age, mean or median age, gender, follow-up duration, albumin and globulin level, mortality, cut-off value, HR of each clinical outcomes (OS, CSS, DFS/RFS, and DMFS), 95\%CI and $\mathrm{p}$ value (Figure 1). HRs would be extracted or calculated from the Kaplan-Meier Curves if they were not directly provided in the articles.

\section{Statistical analysis}

A systemic review and meta-analysis was performed to illustrate the prognostic value of AGR 
and OS of patients with solid tumors. The secondary outcomes were DFS/RFS, CSS and DMFS. HRs and 95\% CIs of the outcomes were extracted from the articles. When the data were not reported in the articles, HRs and their 95\% CIs would be calculated from the provided data or specific points in the Kaplan-Meier Curves using the methods from Parmar et. al ${ }^{[32]}$. In order to minimize this interference induced by the number of studies, $\mathrm{I}^{2}$ test was used to estimate the variation across the studies instead of the $Q$ test, because $Q$ test results were closely related to the number of included studies. The $\mathrm{I}^{2}$ was calculated by the formula: $\mathrm{I}^{2}=\frac{100 \% \times(Q-d f)}{Q} ; \mathrm{Q}$ stood for $\mathrm{a}$ heterogeneity statistic and df was defined as the degree of freedom $(\mathrm{df}=$ total number of trials -1$)$. The heterogeneity was defined as low (25\%-49\%), moderate $(50 \%-74 \%)$ or severe $(>75 \%)$. Fixed-effect analysis model was used to calculate the HR. Heterogeneity would be considered as significant if the $p$ values less than 0.1 . If it was severe, a random-effect analysis model would be used. In addition, the sensitivity test or subgroup analysis would be performed. In terms of specific categories, subgroup analyses were conducted according to cancer types, disease stages and AGR cut-off value. Z-test was performed to calculate the $\mathrm{p}$ value, which was two-sided and defined as statistically different when $p<0.05$. No publication bias was observed via Begg test and Egger test in the analysis. The statistical analysis was conducted via the comprehensive meta-analysis program (Version 3, Biostat, Englewood, NJ USA).

\section{Results}

\section{Selection process and cohort characteristics}

A search of electronic databases revealed a total of 491 potential articles for analysis. Among them, 25 articles were excluded as duplicate data. A number of 466 full-text articles were selected for further investigation, while no extra article was included from other source. After apply the exclusion criteria, 445 articles had to be excluded from the analysis. Finally, a total of 21 studies were chosen for data extraction and meta-analysis[15-36]. The selection process and the reasons for exclusion were demonstrated in the diagram (Figure 1). All studies were retrospective. Among them, cancers from digestive system accounted for the largest proportion $(11 / 24)$ including colorectal cancer, gastric cancer, esophageal cancer and hepatocellular cancer. Referring to the disease stage, 18 studies were 21 studies determined AGR cut-off values via ROC sensitivity and specificity analysis (Youden index or Concordance Index), while 3 studies determined their cut-off values by tertiles and one study provided no information about the method of deciding AGR cut-off value. The characteristics of studies were shown in Table 1.

\section{Overall survival}

A number of 13890 patients were included from 24 articles for the analysis of overall survival (OS). Compared to lower AGR patients, higher AGR patients had better overall survival (HR=0.580, 95\% CI $0.537-0.626, \mathrm{p}<0.001$, Figure 2). Due to the heterogeneity, the random-effect model was utilized $\left(\mathrm{I}^{2}=67.4 \%, \mathrm{p}<0.001\right)$. In the subgroup analysis, it showed that higher AGR was associated with an ideal overall survival in each type of malignancies (Table 2). The cut-off values from studies varied from 0.7 to 1.75. Therefore, we separated the included studies into 3 categories according to the tertile interval of the cut-off values. There were 6 studies in $\leq 1.20$ group, 9 studies in $>1.20$ to $<1.40$ group and 6 studies in $\geq 1.40$ group. We observed the same results in three subgroups that higher AGR predicted better overall survival (Group1: HR=0.371, 95\% CI 0.235-0.586, $\mathrm{p}<0.001$; Group2: HR=0.573, 95\%CI 0.489-0.671, $\mathrm{p}<0.001$; Group3: HR=0.617, 95\%CI 0.550-0.692, $\mathrm{p}<0.001$ ). In terms of disease stage, high AGR was related to better prognosis in metastatic disease $(\mathrm{HR}=0.49, \quad 95 \% \mathrm{CI} \quad 0.28-0.87, \quad \mathrm{p}<0.001), \quad$ in non-metastatic disease (HR=0.61, 95\% CI 0.54-0.72, $\mathrm{p}<0.001)$ and in mixed group including metastatic and non-metastatic diseases (HR=0.57, 95\% CI 0.516-0.625, $\mathrm{p}<0.001)$.

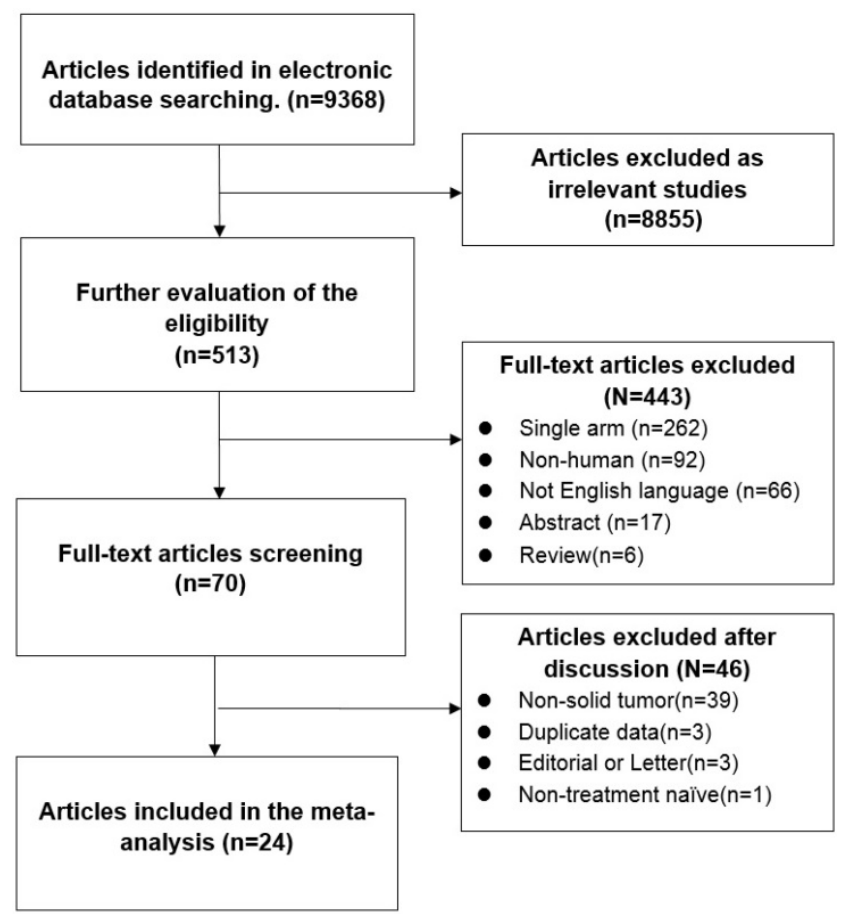

Figure 1. The diagram of articles selection process 
Table 1. The characteristics of the included studies

\begin{tabular}{|c|c|c|c|c|c|c|c|c|c|}
\hline Author & Year & Cancer Type & Duration & Region & Disease stage & No. & Age(Median) & Follow-up(Median) & Cut-off \\
\hline Azab (I) & 2013 & $\begin{array}{l}\text { Colorectal } \\
\text { Cancer }\end{array}$ & $2005-2011$ & USA & Mixed & 534 & $69^{*}$ & 40 & $<1.028,[1.028-1.321],>1.321$ (tertile) \\
\hline Azab (II) & 2013 & Breast Cancer & 2004-2006 & USA & Mixed & 354 & $63.7^{*}$ & 48 & $<1.21,[1.21-1.45],>1.45$ (tertile) \\
\hline Duran & 2014 & $\begin{array}{l}\text { Lung } \\
\text { Adenocarcinoma }\end{array}$ & $2007-2011$ & Turkey & Mixed & 240 & $58.7^{*}$ & NA & $0.7,1.0,1.4$ (average) \\
\hline $\mathrm{Du}$ & 2014 & $\begin{array}{l}\text { Nasopharyngeal } \\
\text { Carcinoma }\end{array}$ & 2003-2006 & China & Mixed & 694 & $44(13-78)$ & $88(5-123)$ & $<1.4$ \\
\hline Chen & 2015 & Gastric Cancer & $2007-2010$ & China & Mixed & 186 & $61(19-82)$ & NA & $\leq 1.33$ \\
\hline $\mathrm{Li}$ & 2015 & $\begin{array}{l}\text { Nasopharyngeal } \\
\text { Carcinoma }\end{array}$ & 2001-2009 & China & Mixed & 520 & $43(13-78)$ & $88.4(4.2-150.6)$ & $\leq 1.34$ \\
\hline Shibutani & 2015 & $\begin{array}{l}\text { Metastatic } \\
\text { Colorectal } \\
\text { Cancer }\end{array}$ & 2006-2011 & Japan & Metastatic & 66 & $63(36-80)$ & NA & $\leq 1.25$ \\
\hline Zhang & 2015 & $\begin{array}{l}\text { Upper Tract } \\
\text { Urothelial } \\
\text { Carcinoma }\end{array}$ & 2006-2008 & China & Mixed & 187 & $70(61-74) ※$ & $78(32-92) ※$ & $<1.45$ \\
\hline Qingguo Li & 2015 & Rectal Cancer & 2006-2012 & China & Mixed & 293 & NA & NA & $\leq 1.2$ \\
\hline Deng & 2016 & $\begin{array}{l}\text { Hepatocellular } \\
\text { Carcinoma }\end{array}$ & 2002-2012 & China & Non-metastatic & 172 & $53(24-80)$ & NA & $<1.48$ \\
\hline Liu & 2016 & $\begin{array}{l}\text { Bladder } \\
\text { Urothelial } \\
\text { Carcinoma }\end{array}$ & 2000-2013 & China & Non-metastatic & 296 & $61.7(33-89)$ & $72(49-121) ※$ & $<1.60$ \\
\hline Toiyama & 2016 & Gastric Cancer & 2001-2011 & Japan & Mixed & 384 & $67(32-88)$ & 47.6 & $\leq 1.38$ \\
\hline Yaqi Li & 2016 & $\begin{array}{l}\text { Colorectal } \\
\text { Cancer }\end{array}$ & 2007-2014 & China & Non-metastatic & 5336 & $59(51-66) ※$ & 55.2 & $<1.5$ \\
\hline Zhang & 2016 & $\begin{array}{l}\text { Hepatocellular } \\
\text { Carcinoma }\end{array}$ & 2008-2012 & China & Mixed & 105 & $49(24-72)$ & NA & $<1.18$ \\
\hline Zhou(training) & 2016 & $\begin{array}{l}\text { Small Cell Lung } \\
\text { Cancer }\end{array}$ & 2003-2009 & China & Mixed & 276 & $59(52-66) ※$ & NA & $<1.29$ \\
\hline $\begin{array}{l}\text { Zhou } \\
\text { (validation) }\end{array}$ & 2016 & $\begin{array}{l}\text { Small Cell Lung } \\
\text { Cancer }\end{array}$ & 2008-2011 & China & Mixed & 379 & $60(54-66) ※$ & NA & $<1.29$ \\
\hline Fei Zhang, & 2016 & $\begin{array}{l}\text { Esophageal } \\
\text { Squamous Cell } \\
\text { Carcinoma }\end{array}$ & 2006-2010 & China & Mixed & 458 & $59(20-88)$ & NA & $<1.30$ \\
\hline Asude Aksoy & 2016 & $\begin{array}{l}\text { Gastric } \\
\text { Carcinoma }\end{array}$ & 2009-2014 & Turkey & Metastatic & 204 & $59^{*}$ & $66.39^{*}$ & 1.14 \\
\hline Chen & 2016 & $\begin{array}{l}\text { Clear Cell Renal } \\
\text { Cell Carcinoma }\end{array}$ & 2003-2013 & China & Mixed & 416 & $56.3(24-80)$ & 69.2(1-151) & $\leq 1.22$ \\
\hline $\mathrm{He}$ & 2017 & $\begin{array}{l}\text { Renal Cell } \\
\text { Carcinoma }\end{array}$ & 2000-2012 & China & Mixed & 895 & $51.44 \pm 13.44^{*}$ & 69.68 & $\leq 1.47$ \\
\hline $\mathrm{Xu}$ & 2017 & Glioblastoma & 2010-2015 & China & Non-metastatic & 166 & $50.41 \pm 14.5^{*}$ & $14(1-52)$ & $\leq 1.75$ \\
\hline $\begin{array}{l}\text { Hiroyuki } \\
\text { Fujikawa }\end{array}$ & 2017 & Colon Cancer & 2002-2012 & Japan & Non-metastatic & 248 & $70(27-88)$ & $49.7(46.8-57.0)$ & $<1.32$ \\
\hline Mao(Testing) & 2017 & Gastric Cancer & 2009-2013 & China & Mixed & 431 & $59(26-85)$ & NA & $\leq 1.5$ \\
\hline Mao(Validate) & 2017 & Gastric Cancer & 2009-2013 & China & Mixed & 431 & $59(26-85)$ & NA & $\leq 1.5$ \\
\hline Oki & 2017 & $\begin{array}{l}\text { Esophageal } \\
\text { Cancer }\end{array}$ & 2002-2014 & Japan & Mixed & 112 & $68(41-90)$ & $24.9(27.6-36.2)$ & $\leq 1.41$ \\
\hline Liu & 2017 & Gastric Cancer & 2005-2012 & China & Non-metastatic & 507 & 58.8 & NA & $<1.93$ \\
\hline
\end{tabular}

\section{Disease-free survival or Recurrence-free survival}

A total of 6541 patients in 6 studies were available for disease-free survival (DFS) or recurrence-free survival (RFS) data extraction $[25-27,30,33$, 35]. Patients whose AGRs were higher than cut-off value had better clinical outcomes (HR $=0.792,95 \% \mathrm{CI}$ $0.715-0.878, \mathrm{p}<0.001$; Figure 3$)$. The random-effect model was utilized due to the significant heterogeneity $\left(\mathrm{I}^{2}=67.1 \%\right.$, $\left.\mathrm{p}=0.01\right)$.

\section{Distant metastasis-free survival and Cancer-specific survival}

Only 2 studies including 1214 patients had reported the distant metastasis-free survival (DMFS) data[17, 19]. The result of analysis showed that high AGR was associated with ideal DMFS (HR $=0.595$, 95\% CI 0.447-0.792, $\mathrm{p}<0.001)$. The fixed-effect model was selected while the heterogeneity was insignificant $\left(\mathrm{I}^{2}=8.73, \mathrm{p}=0.295\right)$ (Figure 4).

\section{Cancer-specific survival}

A total of 3 studies comprising 899 patients reported the cancer-specific survival (CSS)[22, 24, 27]. Better prognostic outcomes were observed in higher AGR patients in terms of CSS ( $\mathrm{HR}=0.287,95 \% \mathrm{CI}$ $0.187-0.438, \mathrm{p}<0.001)$. According to the significant heterogeneity, the random-effect model was used in CSS analysis $\left(\mathrm{I}^{2}=73.65, \mathrm{p}=0.022\right)$. 


\section{Discussion}

Albumin accounts for the largest proportion of serum protein which plays a crucial role of human body. A normal level of albumin $(>3.5 \mathrm{~g} / \mathrm{dl})$ is indispensable in the physiological activities of human body. It is generated by liver and acting as one of the biomarkers for liver function evaluation (Child-Pugh) ${ }^{[38]}$. Low albumin was not only associated to the poor nutrition status, but also a negative predictor for clinical outcomes of various malignancies ${ }^{[39-41]}$. Referring to the non-albumin proteins, they are also named as calculated globulins which are calculated by the formula (Total serum proteins-albumin). The calculated globulins contain a large amount of immunity-related proteins such as immunoglobulins, complements, C-reaction proteins (CRP), interleukins, TNF, et.al. Some researchers reported that tumor biomarkers including CA 19-9 and CEA were also considered as calculated globulins ${ }^{[15]}$. Previous studies had showed the predictive value of such inflammatory proteins. High level of compliment 3 (C3) and IgA indicated poor prognosis in colorectal cancer patients. Moreover, C3 and $\mathrm{C} 4$ had been reported to be the negative prognostic factors in NSCLC[42, 43]. Higher CRP level was associated with decreased survival in gastrointestinal cancer and lung cancer patients $[5,44,45]$.

The mechanisms of correlation of AGR and solid tumor survival have not been fully understood. In the previous studies, poor nutrition status (hypoalbuminemia) had been proved to be a negative prognostic factor of long-term survival in many tumors including gastrointestinal, lung, hepatobiliary, CNS, reproductive and breast cancers[15, 46, 47]. Additionally, normal albumin level was reported to be crucial for the drug delivery in chemotherapy ${ }^{[48,49]}$. On the other hand, chronic inflammatory is considered as a contributor for tumor proliferation, immune evasion, and metastasis involving all kinds of serum globulins (CRP, TNF, immunoglobulins, and other cytokines). These serum globulins secreted by tumor-related cells were reported to promote tumor development, angiogenesis, immunosuppression, and metastasis. Therefore, low albumins and high globulins which indicated poor nutrition status and the extent of severe chronic inflammation could decrease the survival of cancer patients.

Chronic inflammation is associated with the occurrence, proliferation, survival, metastasis and the recurrence of cancer [50], The occurrence of tumors involves the interaction between the immune system, interstitial cells and malignant cells. Inflammatory factors promote cell proliferation and induce tumor suppressor gene mutation or cell cacinogenesis by altering the cell microenvironment.

The presence of inflammation is conducive to the occurrence of cancer. On the other hand, the tumor has exacerbated the inflammatory response. Chronic inflammation regulates $T$ cells, Th2 cells and activated B cells accumulate. The polarization effect of multiple cytokines on tumor related macrophages is mediated. Ultimat- 
ely, it leads to the development and progression of cancer[51]. Tumor-associated macrophages and inflammatory cytokines promote tumor growth, progression, angiogenesis metastasis and immunosuppression [51-54].

\section{Hazard ratios for disease-free survival or recurence-free survival}

\begin{tabular}{lccccc} 
Study name & \multicolumn{5}{c}{ Statistics for each study } \\
\cline { 2 - 6 } & $\begin{array}{c}\text { Hazard } \\
\text { ratio }\end{array}$ & $\begin{array}{c}\text { Lower } \\
\text { limit }\end{array}$ & $\begin{array}{c}\text { Upper } \\
\text { limit }\end{array}$ & Z-Value & p-Value \\
Deng,2016 & 0.493 & 0.293 & 0.829 & -2.669 & 0.008 \\
Liu,2016 & 0.356 & 0.170 & 0.747 & -2.733 & 0.006 \\
Toiyama,2016 & 0.579 & 0.337 & 0.996 & -1.975 & 0.048 \\
Yaqi Li,2016 & 0.857 & 0.765 & 0.960 & -2.664 & 0.008 \\
Zhang,2016 & 0.730 & 0.494 & 1.078 & -1.581 & 0.114 \\
Hiroyuki Fujikawa,2017 & 0.341 & 0.152 & 0.763 & -2.618 & 0.009 \\
Oki,2017 & 0.370 & 0.161 & 0.853 & -2.334 & 0.020 \\
& 0.783 & 0.707 & 0.867 & -4.697 & 0.000
\end{tabular}

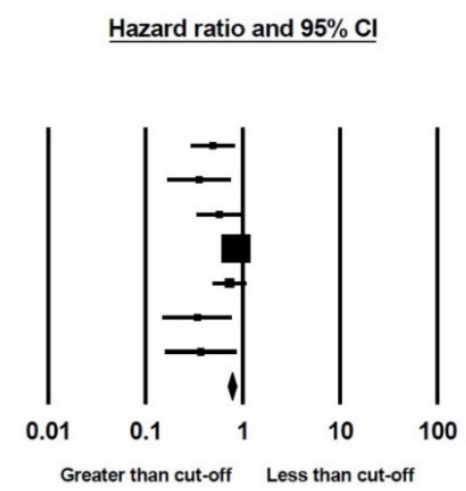

Meta Analysis

Figure 3. Forest plot of hazard ratio for the disease-free survival or recurrence-free survival

Hazard ratio for distant metastasis-free survival

\begin{tabular}{|c|c|c|c|c|c|c|c|c|c|}
\hline \multirow[t]{2}{*}{ Study name } & \multicolumn{5}{|c|}{ Statistics for each study } & \multicolumn{4}{|c|}{ Hazard ratio and $95 \% \mathrm{CI}$} \\
\hline & $\begin{array}{l}\text { Hazard } \\
\text { ratio }\end{array}$ & $\begin{array}{c}\text { Lower } \\
\text { limit }\end{array}$ & $\begin{array}{l}\text { Upper } \\
\text { limit }\end{array}$ & Z-Value & p-Value & & & & \\
\hline Du,2014 & 0.672 & 0.466 & 0.969 & -2.131 & 0.033 & I & I & | & | \\
\hline \multirow[t]{4}{*}{ Li,2015 } & 0.491 & 0.310 & 0.778 & -3.030 & 0.002 & & & & \\
\hline & 0.595 & 0.447 & 0.792 & -3.554 & 0.000 & & & & \\
\hline & & & & & & 0.01 & 0.1 & 10 & 100 \\
\hline & & & & & & \multicolumn{4}{|c|}{ Greater than cut-off Less than cut-off } \\
\hline
\end{tabular}

Figure 4. Forest plot of hazard ratio for the disease metastasis-free survival

\section{Hazard ratio for cancer-specific death}

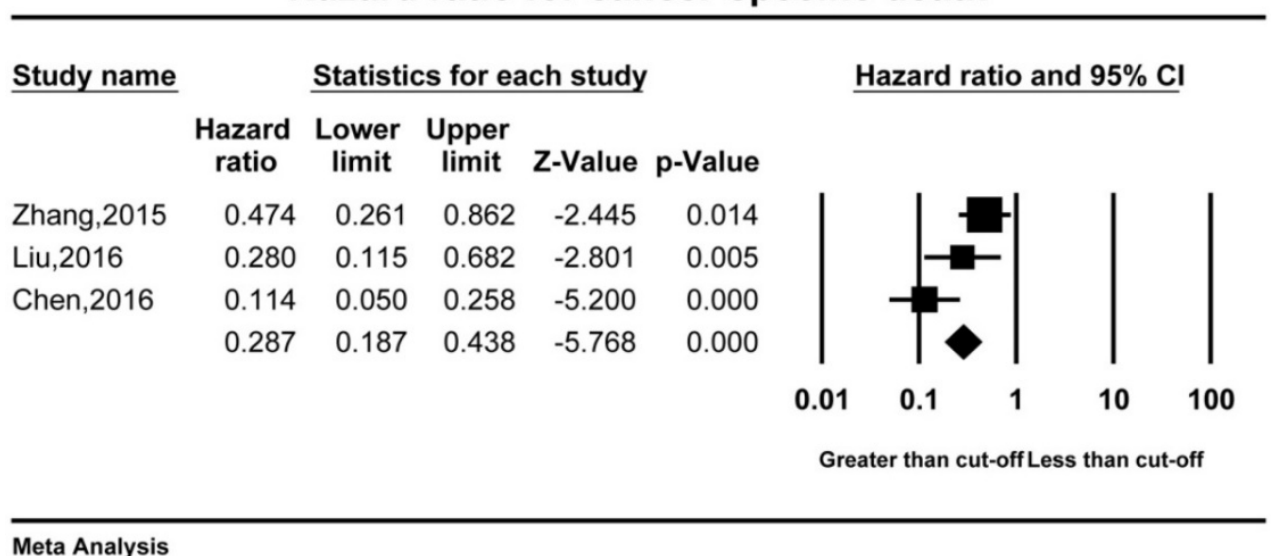

Figure 5. Forest plot of hazard ratio for the cancer-specific survival 
Instead of albumins and globulins absolute levels, AGR was a ratio which was a combination of two independent prognostic factors. Since the albumins and globulins were conversely correlated to the solid tumor survival, AGR was more significant and precise to demonstrate the prognostic effect. Firstly, it greatly decreased the possible influence from the variation of albumins or globulins which might be generated by measurement error or abnormal situations including fluid retention and dehydration. Besides, both variations from albumins and globulins would result in AGR changes synchronously. Therefore, we believed AGR was capable for outcomes evaluation.

Dias et.al firstly reported that AGR was lower in retinoblastoma patients comparing to the control[55]. Further, Cohen et.al reported that both low albumins and high immunoglobulins had negative effect in small cell lung cancer prognosis ${ }^{[3]}$. However, few studies had reported the prognostic value of AGR in solid tumors. Until recently, numbers of researches had studies the correlation between AGR and the survival outcomes of solid tumor. Considering the absence of consensus on AGR and outcomes of solid tumor, we therefore performed this analysis. The results showed that high AGR was associated with favorable OS, DFS, DMFS and CSS. Besides, the results of subgroup analysis including disease stage, tumor types, and different cut-off value, demonstrated an ideal concordance that higher AGR had a positive effect to the overall survival of patients with solid tumors.

Table 2. The hazard ratio for overall survival in different subgroups: tumor type, disease stage and cut-off value

\begin{tabular}{|c|c|c|c|c|}
\hline & No. & HR & $95 \% \mathrm{CI}$ & P value \\
\hline \multicolumn{5}{|l|}{ Tumor type } \\
\hline Colorectal cancer & 5 & 0.505 & $0.399-0.640$ & $<0.001$ \\
\hline Breast cancer & 1 & 0.242 & $0.139-0.422$ & $<0.001$ \\
\hline Lung Adenocarcinoma & 1 & 0.687 & $0.535-0.883$ & 0.003 \\
\hline Nasopharyngeal Carcinoma & 2 & 0.695 & $0.502-0.963$ & 0.029 \\
\hline Gastric cancer & 5 & 0.609 & $0.504-0.738$ & $<0.001$ \\
\hline $\begin{array}{l}\text { Upper tract urothelial } \\
\text { carcinoma }\end{array}$ & 2 & 0.452 & $0.271-0.751$ & 0.002 \\
\hline Hepatocellular carcinoma & 2 & 0.296 & $0.195-0.448$ & $<0.001$ \\
\hline Small cell lung cancer & 1 & 0.721 & $0.582-0.893$ & 0.003 \\
\hline $\begin{array}{l}\text { Esophageal Squamous cell } \\
\text { carcinoma }\end{array}$ & 1 & 0.759 & $0.507-1.137$ & 0.181 \\
\hline Esophageal Carcinoma(Mixed) & 1 & 0.47 & $0.240-0.920$ & 0.028 \\
\hline Clear cell renal cell carcinoma & 2 & 0.473 & $0.335-0.668$ & $<0.001$ \\
\hline Glioblastoma & 1 & 0.785 & $0.357-0.979$ & 0.04 \\
\hline \multicolumn{5}{|l|}{ Disease stage } \\
\hline non-metastatic & 5 & 0.61 & $0.54-0.72$ & $<0.001$ \\
\hline metastatic & 2 & 0.49 & $0.28-0.87$ & $<0.001$ \\
\hline mixed & 17 & 0.57 & $0.52-0.62$ & $<0.001$ \\
\hline \multicolumn{5}{|l|}{ Cut-off value } \\
\hline$\leq 1.20$ & 6 & 0.371 & $0.235-0.586$ & $<0.001$ \\
\hline$>1.20$ to $<1.40$ & 9 & 0.573 & $0.489-0.671$ & $<0.001$ \\
\hline$\geq 1.40$ & 9 & 0.617 & $0.550-0.692$ & $<0.001$ \\
\hline Overall & 24 & 0.578 & $0.533-0.626$ & $<0.001$ \\
\hline
\end{tabular}

Limitations should be admitted in this study. First, the original data from the included studies were not available. As a result, the analysis had to be performed via extracted data from the articles. Additionally, the included articles were retrospective studies. A large proportion of them provided HRs, $95 \% \mathrm{CI}$ and $\mathrm{p}$ values from the univariate analysis. However, these data were not available in some studies that we had to estimate HR and $95 \% \mathrm{CI}$ from Kaplan-Meier curve. It could lead to overestimation of the prognostic effect. Second, a moderate heterogeneity was observed between studies in OS analysis. Therefore, the random-effect model was selected. The sensitivity test was performed to identify the study contributing most to the heterogeneity. The result was not influenced by the deletion of the study. Third, the cut-off values from the included studies were inconsistent since they had been verified from different tumors or even different methods. Among them, the cut-off values from 3 studies were identified as the tertile interval. Therefore, it was unable to verify in this study.

In summary, our study indicates that high AGR has significant positive prognostic effect on the survival in different solid tumor patients including both non-metastatic and metastatic patients. AGR is useful and available in the clinical practice. Further investigation and research are warranted to verify its role in the diagnosis and evaluation of the solid tumor. Moreover, the specific cut-off value of AGR in each type of cancer should be identify and validated.

\section{Abbreviations}

AGR: Albumin-to-globulin ratio; OS: Overall survival; DFS: Disease-free survival; RFS: Recurrence-free survival; DMFS: Disease metastasis-free survival; CSS: Cancer-specific survival; NSCLC: Non-small cell lung cancer; HR: Hazard ratio; CI: Confidence interval; CRP: C-reaction protein; TNF: Tumor necrosis factor; CEA: Carcino-embryonic antigen.

\section{Availability of data and materials}

The datasets extracted and analyzed during the current study are available in the PMC, PubMed, Embase, Web of Science, Cochrane Central Register of Controlled Trial, Cochrane Database of Systematic Reviews, and ACP Journal Club and Database of Abstracts of Reviews of Effects repository.

\section{Authors' contribution}

Jiaxi $\mathrm{He}$ and H.P designed research and contributed to the data analysis and interpretation. Jiaxi He and WH.L wrote the manuscript. XW.C and 
MZ.G collected data. WH.L, H.P and DK.X contributed to the data interpretation and manuscript revision. Jianxing He approved the final version of manuscript and submitted.

\section{Competing Interests}

The authors have declared that no competing interest exists.

\section{References}

[1] Ataseven B, du Bois A, Reinthaller A, Traut A, Heitz F, Aust S, et al. Pre-operative serum albumin is associated with post-operative complication rate and overall survival in patients with epithelial ovarian cancer undergoing cytoreductive surgery. Gynecol Oncol. 2015;138(3):560-5.

[2] Chiang JM, Chang CJ, Jiang SF, Yeh CY, You JF, Hsieh PS, et al. Pre-operative serum albumin level substantially predicts post-operative morbidity and mortality among patients with colorectal cancer who undergo elective colectomy. Eur J Cancer Care (Engl). 2017;26(2)

[3] Ishizuka M, Nagata H, Takagi K, Iwasaki Y, Shibuya N, Kubota K. Clinical Significance of the C-Reactive Protein to Albumin Ratio for Survival After Surgery for Colorectal Cancer. Ann Surg Oncol. 2016;23(3):900-7.

[4] Jiang H, Li H, Li A, Tang E, Xu D, Chen Y, et al. Preoperative combined hemoglobin, albumin, lymphocyte and platelet levels predict survival in patients with locally advanced colorectal cancer. Oncotarget. 2016;7(44):72076-83.

[5] Zhou T, Zhan J, Hong S, Hu Z, Fang W, Qin T, et al. Ratio of C-Reactive Protein/Albumin is An Inflammatory Prognostic Score for Predicting Overall Survival of Patients with Small-cell Lung Cancer. Sci Rep. 2015;5:10481.

[6] Gabay C, Kushner I. Acute-phase proteins and other systemic responses to inflammation. N Engl J Med. 1999:340(6):448-54.

[7] McMillan DC, Watson WS, O'Gorman P, Preston T, Scott HR, McArdle CS. Albumin concentrations are primarily determined by the body cell mass and the systemic inflammatory response in cancer patients with weight loss. Nutr Cancer. 2001;39(2):210-3.

[8] Wang H, Xu H, Qu L, Wang X, Wu R, Gao X, et al. Red blood cell distribution width and globulin, noninvasive indicators of fibrosis and inflammation in chronic hepatitis patients. Eur J Gastroenterol Hepatol. 2016;28(9):997-1002

[9] Kratz F, Beyer U. Serum proteins as drug carriers of anticancer agents: a review. Drug delivery. 1998;5(4):281-99.

[10] Gabay C, Kushner I. Acute-phase proteins and other systemic responses to inflammation. The New England journal of medicine. 1999;340(6):448-54.

[11] Sinclair D, Wainwright L. How lab staff and the estimation of free light chains can combine to aid the diagnosis of light chain disease. Clinical laboratory. 2007;53(5-6):267-71.

[12] Franklin EC. Two types of gamma-1A-globulin in sera from normals and patients with multiple myeloma. Nature. 1962;195:393-4.

[13] Li YJ, Li ZM, Xia Y, Huang JJ, Huang HQ Xia ZJ, et al. Serum C-reactive protein (CRP) as a simple and independent prognostic factor in extranodal natural killer/T-cell lymphoma, nasal type. PloS one. 2013;8(5):e64158.

[14] Bi XW, Wang L, Zhang WW, Yan SM, Sun P, Xia Y, et al. The pretreatment albumin to globulin ratio predicts survival in patients with natural killer/T-cell lymphoma. PeerJ. 2016;4:e1742.

[15] Azab B, Kedia S, Shah N, Vonfrolio S, Lu W, Naboush A, et al. The value of the pretreatment albumin/globulin ratio in predicting the long-term survival in colorectal cancer. Int J Colorectal Dis. 2013;28(12):1629-36.

[16] Azab BN, Bhatt VR, Vonfrolio S, Bachir R, Rubinshteyn V, Alkaied H, et al. Value of the pretreatment albumin to globulin ratio in predicting long-term mortality in breast cancer patients. Am J Surg. 2013;206(5):764-70.

[17] Du XJ, Tang LL, Mao YP, Sun Y, Zeng MS, Kang TB, et al. The pretreatment albumin to globulin ratio has predictive value for long-term mortality in nasopharyngeal carcinoma. PLoS One. 2014;9(4):e94473.

[18] Duran AO, Inanc M, Karaca H, Dogan I, Berk V, Bozkurt O, et al. Albumin-globulin ratio for prediction of long-term mortality in lung adenocarcinoma patients. Asian Pac J Cancer Prev. 2014;15(15):6449-53.

[19] Li AC, Xiao WW, Wang L, Shen GZ, Xu AA, Cao YQ, et al. Risk factors and prediction-score model for distant metastasis in nasopharyngeal carcinoma treated with intensity-modulated radiotherapy. Tumour Biol. 2015;36(11):8349-57.

[20] Li Q, Meng X, Liang L, Xu Y, Cai G, Cai S. High preoperative serum globulin in rectal cancer treated with neoadjunctive chemoradiation therapy is a risk factor for poor outcome. Am J Cancer Res. 2015;5(9):2856-64.

[21] Shibutani M, Maeda K, Nagahara H, Ohtani H, Iseki Y, Ikeya T, et al. The pretreatment albumin to globulin ratio predicts chemotherapeutic outcomes in patients with unresectable metastatic colorectal cancer. BMC Cancer. 2015;15:347.

[22] Zhang B, Yu W, Zhou LQ, He ZS, Shen C, He Q, et al. Prognostic Significance of Preoperative Albumin-Globulin Ratio in Patients with Upper Tract Urothelial Carcinoma. PLoS One. 2015;10(12):e0144961.
[23] Aksoy A, Durak S, Ozturk T, Avci N, Cirak Y, Deger AN, et al. The Albumin-Globulin Ratio Predicting Mortality in Gastric Carcinoma. Acta Medica Mediterr. 2016;32(3):707-12

[24] Chen J, Zhou Y, Xu Y, Zhu HY, Shi YQ. Low pretreatment serum globulin may predict favorable prognosis for gastric cancer patients. Tumour Biol. 2016;37(3):3905-11.

[25] Deng Y, Pang Q, Miao RC, Chen W, Zhou YY, Bi JB, et al. Prognostic significance of pretreatment albumin/globulin ratio in patients with hepatocellular carcinoma. Onco Targets Ther. 2016;9:5317-28.

[26] Li Y, Jia H, Yu W, Xu Y, Li X, Li Q, et al. Nomograms for predicting prognostic value of inflammatory biomarkers in colorectal cancer patients after radical resection. Int J Cancer. 2016;139(1):220-31.

[27] Liu J, Dai Y, Zhou F, Long Z, Li Y, Liu B, et al. The prognostic role of preoperative serum albumin/globulin ratio in patients with bladder urothelial carcinoma undergoing radical cystectomy. Urol Oncol. 2016;34(11):484 e1- e8.

[28] Park S, Park S, Lee SH, Suh B, Ock CY, Keam B, et al. Pretreatment albumin-to-globulin ratio as a predictive marker for tyrosine kinase inhibitor in non-small cell lung cancer. Cancer Biomark. 2016;16(3):425-33.

[29] Zhang F, Sun P, Wang ZQ, Wang de S, Wang Y, Zhang DS, et al. Low preoperative albumin-globulin score predicts favorable survival in esophageal squamous cell carcinoma. Oncotarget. 2016;7(21):30550-60

[30] Zhang J, Liu X, Yang Z, Chen Y, Luo R. The pretreatment albumin to globulin ratio, a validated biomarker, predicts prognosis in hepatocellular carcinoma. J BUON. 2016;21(4):925-34.

[31] Zhou T, He X, Fang W, Zhan J, Hong S, Qin T, et al. Pretreatment Albumin/Globulin Ratio Predicts the Prognosis for Small-Cell Lung Cancer. Medicine (Baltimore). 2016;95(12):e3097.

[32] Chen Z, Shao Y, Yao H, Zhuang $Q$, Wang K, Xing Z, et al. Preoperative albumin to globulin ratio predicts survival in clear cell renal cell carcinoma patients. Oncotarget. 2017.

[33] Fujikawa $H$, Toiyama $Y$, Inoue $Y$, Imaoka $H$, Shimura $T$, Okigami $M$, et al. Prognostic Impact of Preoperative Albumin-to-Globulin Ratio in Patients with Colon Cancer Undergoing Surgery with Curative Intent. Anticancer Res. 2017;37(3):1335-42

[34] He X, Guo S, Chen D, Yang G, Chen X, Zhang Y, et al. Preoperative Albumin to Globulin Ratio (AGR) as Prognostic Factor in Renal Cell Carcinoma. J Cancer. 2017;8(2):258-65.

[35] Toiyama Y, Yasuda H, Ohi M, Yoshiyama S, Araki T, Tanaka K, et al. Clinical impact of preoperative albumin to globulin ratio in gastric cancer patients with curative intent. Am J Surg. 2017;213(1):120-6.

[36] Xu WZ, Li F, Xu ZK, Chen X, Sun B, Cao JW, et al. Preoperative albumin-to-globulin ratio and prognostic nutrition index predict prognosis for glioblastoma. Onco Targets Ther. 2017;10:725-33.

[37] Parmar MK, Torri V, Stewart L. Extracting summary statistics to perform meta-analyses of the published literature for survival endpoints. Stat Med. 1998;17(24):2815-34.

[38] Cholongitas E, Papatheodoridis GV, Vangeli M, Terreni N, Patch D, Burroughs AK. Systematic review: The model for end-stage liver disease--should it replace Child-Pugh's classification for assessing prognosis in cirrhosis? Aliment Pharmacol Ther. 2005;22(11-12):1079-89.

[39] Kang SC, Kim HI, Kim MG. Low Serum Albumin Level, Male Sex, and Total Gastrectomy Are Risk Factors of Severe Postoperative Complications in Elderly Gastric Cancer Patients. J Gastric Cancer. 2016;16(1):43-50.

[40] Sejima T, Iwamoto H, Masago T, Morizane S, Yao A, Isoyama T, et al. Low pre-operative levels of serum albumin predict lymph node metastases and ultimately correlate with a biochemical recurrence of prostate cancer in radical prostatectomy patients. Cent European J Urol. 2013;66(2):126-32.

[41] Lai CC, You JF, Yeh CY, Chen JS, Tang R, Wang JY, et al. Low preoperative serum albumin in colon cancer: a risk factor for poor outcome. Int J Colorectal Dis. 2011;26(4):473-81.

[42] Oner F, Savas I, Numanoglu N. Immunoglobulins and complement components in patients with lung cancer. Tuberk Toraks. 2004:52(1):19-23.

[43] Cohen MH, Makuch R, Johnston-Early A, Ihde DC, Bunn PA, Jr., Fossieck BE, Jr., et al. Laboratory parameters as an alternative to performance status in prognostic stratification of patients with small cell lung cancer. Cancer Treat Rep. 1981;65(3-4):187-95.

[44] Shimada H, Nabeya Y, Okazumi S, Matsubara H, Shiratori T, Aoki T, et al. Elevation of preoperative serum C-reactive protein level is related to poor prognosis in esophageal squamous cell carcinoma. J Surg Oncol. 2003;83(4):248-52.

[45] Canna K, McArdle PA, McMillan DC, McNicol AM, Smith GW, McKee RF, et al. The relationship between tumour T-lymphocyte infiltration, the systemic inflammatory response and survival in patients undergoing curative resection for colorectal cancer. Br J Cancer. 2005;92(4):651-4.

[46] Gupta D, Lis CG. Pretreatment serum albumin as a predictor of cancer survival: a systematic review of the epidemiological literature. Nutr J. 2010;9:69

[47] Onate-Ocana LF, Aiello-Crocifoglio V, Gallardo-Rincon D, Herrera-Goepfert $\mathrm{R}$, Brom-Valladares $\mathrm{R}$, Carrillo JF, et al. Serum albumin as a significant prognostic factor for patients with gastric carcinoma. Ann Surg Oncol. 2007;14(2):381-9.

[48] Matsumoto I, Tanaka M, Shirakawa S, Shinzeki M, Toyama H, Asari S, et al. Postoperative Serum Albumin Level is a Marker of Incomplete Adjuvant Chemotherapy in Patients with Pancreatic Ductal Adenocarcinoma. Ann Surg Oncol. 2015;22(7):2408-15. 
[49] Arrieta O, Michel Ortega RM, Villanueva-Rodriguez G, Serna-Thome MG, Flores-Estrada D, Diaz-Romero C, et al. Association of nutritional status and serum albumin levels with development of toxicity in patients with advanced non-small cell lung cancer treated with paclitaxel-cisplatin chemotherapy: a prospective study. BMC Cancer. 2010;10:50.

[50] Gast MC, Van Gils CH, Wessels LF, Harris N, Bonfrer JM, Rutgers EJ, et al. Serum protein profiling for diagnosis of breast cancer using SELDI-TOF MS. Oncology reports. 2009;22(1):205-13.

[51] Pierce BL, Ballard-Barbash R, Bernstein L, Baumgartner RN, Neuhouser ML, Wener $\mathrm{MH}$, et al. Elevated biomarkers of inflammation are associated with reduced survival among breast cancer patients. Journal of clinical oncology : official journal of the American Society of Clinical Oncology. 2009;27(21):3437-44.

[52] Gast MC, Van Gils CH, Wessels LF, Harris N, Bonfrer JM, Rutgers EJ, et al. Serum protein profiling for diagnosis of breast cancer using SELDI-TOF MS. Oncology reports. 2009;22(1):205-13.

[53] DeNardo DG, Coussens LM. Inflammation and breast cancer. Balancing immune response: crosstalk between adaptive and innate immune cells during breast cancer progression. Breast cancer research : BCR. 2007;9(4):212.

[54] Mantovani A, Allavena P, Sica A, Balkwill F. Cancer-related inflammation. Nature. 2008;454(7203):436-44.

[55] Dias PL. Postinflammatory and malignant protein patterns in aqueous humour. Br J Ophthalmol. 1979;63(3):161-4. 